
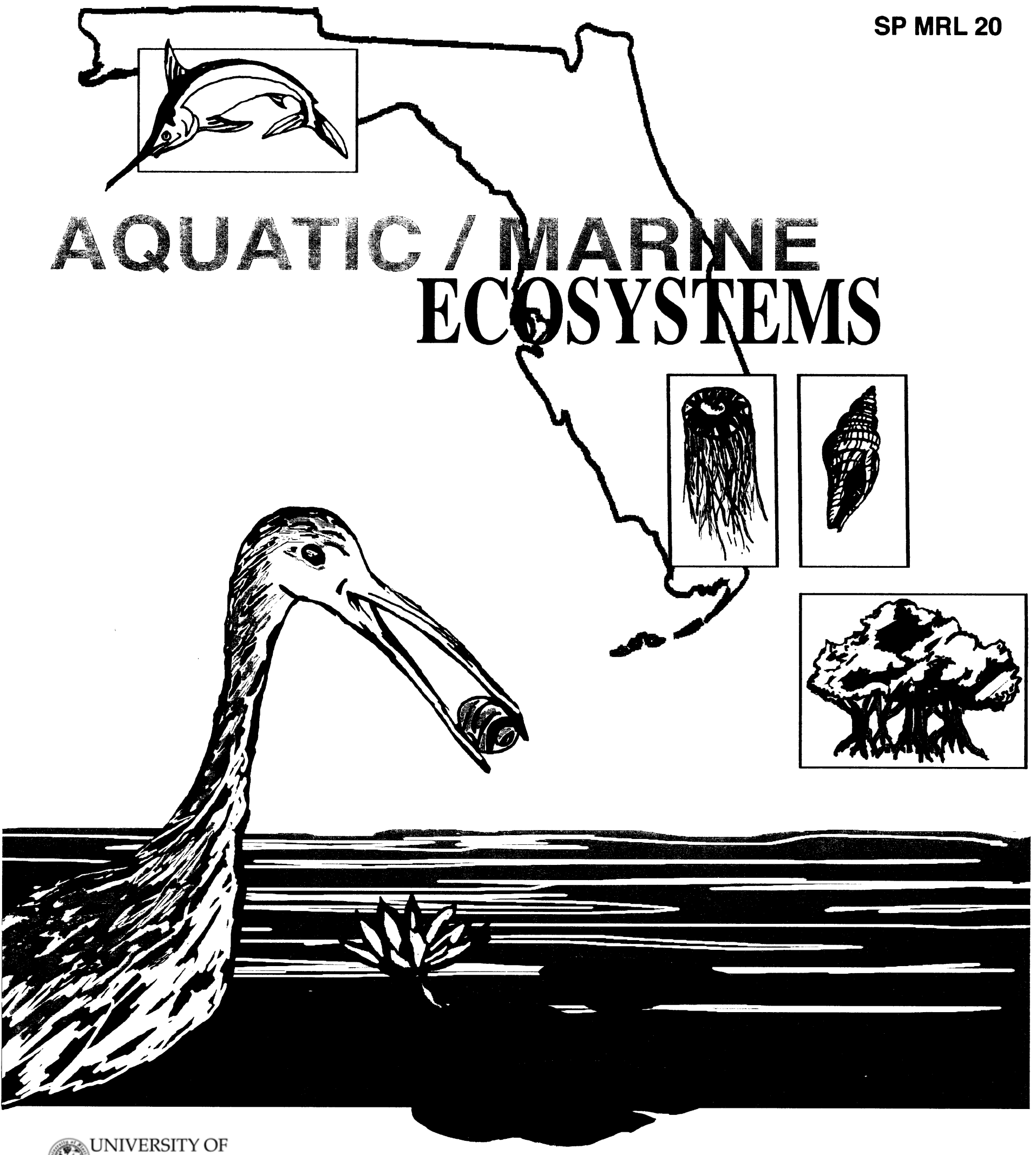


\title{
PREFACE
}

\section{AQUATIC/MARINE ECOSYSTEMS}

\author{
A 4-H Activitiy Guide for 9-14 year olds
}

The new Florida 4-H Aquatic/Marine Ecosystems Leader's Guide, is a part of the Environmental Education Framework, OUR NATURAL WORLD, This framework includes the basic premise that aquatic/marine environments are important in children's lives, particularly to those children in Florida. The 4-H Aquatic/Marine Ecosystems program provides an opportunity for young people to practice a variety of life skills while learning subject matter.

\section{Aquatic/Marine Ecosystems}

Aquatic/Marine Ecosystems is part of the Core Curricula that is designed to help 9-14 year old children understand the role freshwater and marine environments play in our lives and how we as individuals might become better stewards of these environments. Additional curriculum packages are being designed for youth in other age ranges for sequential advancement in the area of aquatic/marine environmental education programs.

To the informed Florida citizen, it is not surprising that educatioal activities related to the aquatic and marine sciences commands a priority within the total Florida4-H education curriculum. An investment in young people's knowledge, understanding and attitudes about these topics will certainly produce a citizen that is better prepared for the decisions of tomorrow. Below you see the framework for the 4-HEnvironmental Education curricula. It charts the direction for development, review and revision.

\section{4-H ENVIRONMENTAL EDUCATION CURRICULUM FRAMEWORK}

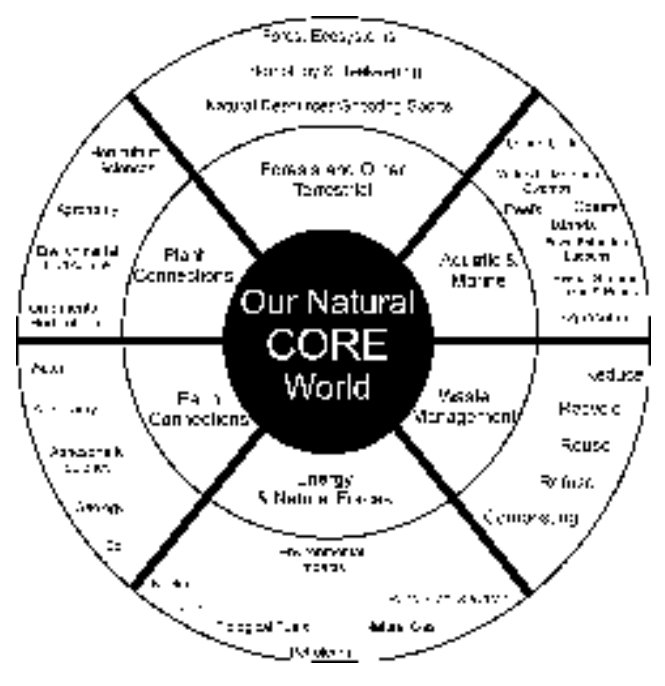




\section{About AQUATIC/MARINE ECOSYSTEMS...}

The development of this 4-H Activity Guide was driven by two basic principles:

1. Learning about the environment can be fun! This leaders guide provides fun, interactive, and educational activities that teach youth about ecological concepts related to Florida's Aquatic/Marine Ecosystems. In addition, the activities in this guide promote the concept of good stewardship in the use and management of these valuable natural resources.

2. 4-H volunteer teaching activities must be ready-to-use. This activity guide includes projects, experiments, games, and activity sheets needed to conduct activities in an easy-to-use format. It was designed to be teacher friendly and takes much of the guesswork out of teaching this subject.

\section{AGE OR GRADE LEVELS}

This project was developed for youth ages 9-14. Both group and individual activities encourage participation and action in all aspects of this program. Because of the large age range, teachers and volunteers are encouraged to select learning activities that are most suitable to their youth, as some activities are more advanced than others. Youths' individual experiences and grade level should be considered when selecting activities. The overall intent is to facilitate learning and to spark creativity in both teachers and youth.

\section{CONTENTS}

The following are components of the AQUATIC/MARINE ECOSYSTEMS LEADER'S GUIDE:

! LESSON INTRODUCTION/BACKGROUND BASICS- This three-ring notebook contains five complete lessons that provide background information for the leader/teacher and help organize activities for the participants. Each lesson is prefaced with a lesson outline and the BACKGROUND BASICS that help you focus on the overall concepts and desired outcomes. Also, to help the leader/teacher, important concepts or critical vocabulary words are in bold and followed by a definition. With this information the leader/teacher can use the lesson as a unit of study or select activities to supplment other curricula. The lesson activities can be adapted and conducted according to needs of the participants and time frame devoted to this project

! LESSON ACTIVITIES - The activities provided in each lesson are specifically designed to guide the learner through specific concepts related to the lesson topic. Objectives for each activity are listed in the activity organizer section along with a materials list, time limitations, setting description, and a list of any advance preparation needed by the leader. Each activity provides an introduction for the participant and a "Do" section. The activity then concludes with discussion questions or suggestions for youth to REFLECT and APPLY the knowledge and skills they have gained. Creative projects, experiments, role playing, and competitions are just a few of the activities found in the leader's guide.

! REFERENCE AND RESOURCE LISTS - These sections are provided at the end of the guide. The REFERENCE LIST contains a number of citations that were used in the production of this guide. It is suggested that these citations be reviewed and if possible acquired for use with the activities. Several of the field guides can be used during those ecosystem exploration activities and should prove invaluable to the serious naturalist. The ADDITIONAL RESOURCE section is provided for those who might want to explore on the world wide web or find additional information through agency publication and other references.

! EVALUATION TOOLS - An evaluation tool is provided to allow you to provide us with feedback about activities in this project. We welcome suggestions and urge you to return this form after you have explored a lesson or two. Simply return the completed evaluation to the address at the bottom of the form. 


\section{TABLE OF CONTENTS}

\section{INTRODUCTION}

Credits ................................. ii

Preface $\ldots \ldots \ldots \ldots \ldots \ldots \ldots \ldots \ldots \ldots \ldots \ldots$ iii

About Aquatic/Marine Ecosystems $\ldots \ldots \ldots \ldots \ldots \ldots \ldots \ldots$ iv

Table of Contents . . . . . . . . . . . . . . . . . . . . vi

Experiential Process... Steps and Techniques $\ldots \ldots \ldots \ldots \ldots \ldots \ldots$

LESSON 1 ECOSYSTEM CONNECTIONS . . . . . . . . . . . . . . 1

Lesson 1 is designed to be a primer for the Aquatic/Marine Leader's Guide. It is suggested that anyone using this guide begin with Lesson 1 and complete all eight activities. The concepts presented here will help set the stage for the remainder of the lessons which are related to specific ecosystems. After completing Lesson 1, the remaining four lessons can be randomly selected depending on the interest of the participants and/or the location relative to the ecosystems under study

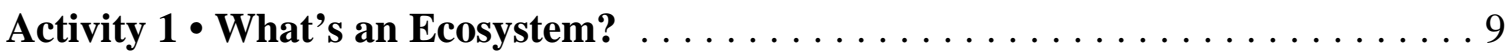
Participants will use maps to locate Florida's aquatic/marine ecosystems and learn how they are related.

Activity 2 • Salt or No Salt, What's the Difference . . . . . . . . . . . . . . 13 Discovering how fish respond to fresh and salt water.

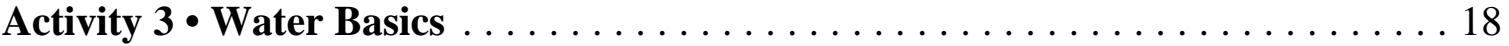
Learning how water cycles.

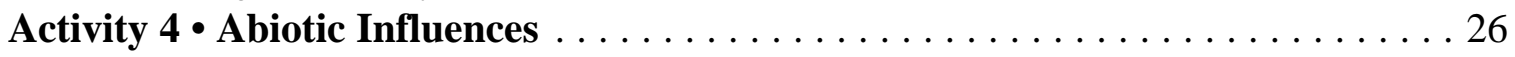

Distinguishing between abiotic (nonliving) and biotic (living) components of an ecosystem.

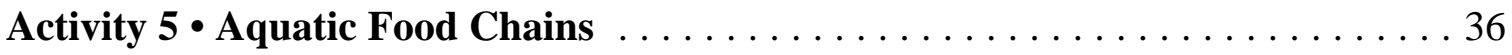
Sampling from a local ecosystem and learning about its energy flow.

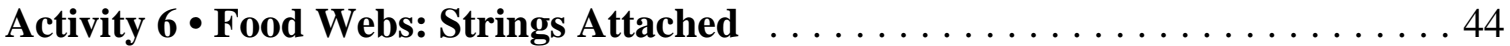
Discover how living and nonliving components of aquatic/marine ecosystems are related.

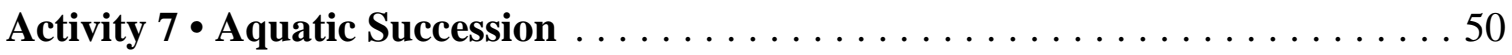
Learning about ecological succession.

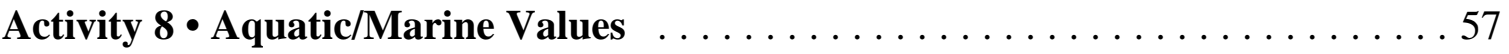
Participants will associate human values with aquatic/marine ecosystems resources.

\section{LESSON 2 WETLAND ECOSYSTEMS}

FRESHWATER MARSHES AND SWAMPS

This Lesson focuses on freshwater wetlands. These most fascinating ecosystems have an important role in Florida. From wildlife sanctuaries to water storage areas, these areas are critical to the survival of endangered species as well as to the ever growing human population. Discover the values of wetlands and the natural functions these habitats provide.

Activity 1 - What is a Wetland?

What do you think a wetland is? Discover what a wetland looks and feels like. Take a 
trip to a freshwater wetland to identify it's characteristics.

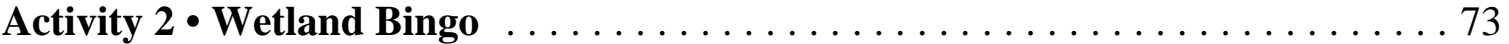

Each plant and animal species has characteristics that make it different from other species.

Discover what lives in freshwater wetlands.

Activity $3 \bullet$ Wetlands Can Store and Filter $\ldots \ldots \ldots \ldots \ldots \ldots \ldots \ldots \ldots \ldots \ldots \ldots$

Learn some of the functions of freshwater wetland areas.

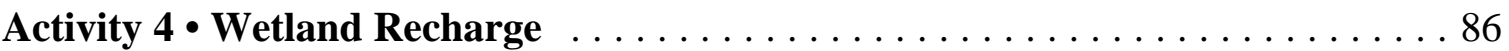

Examine the effects and impacts of the water cycle on wetlands and explore the

effectiveness of wetlands as aquifer recharge areas.

Activity 5

An activity to demonstrate knowledge of food chains and energy flow of wetlands.

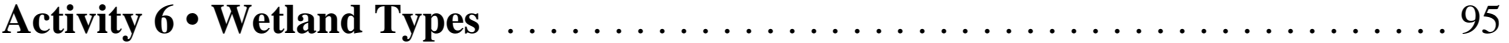

Naming and describing several wetland types will help participants discover the

plants and animals that inhabit each wetland type.

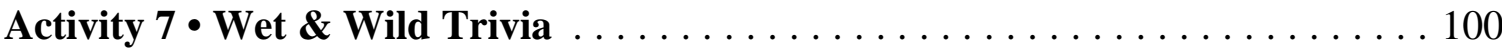

Use this game to test the wetland knowledge of the participants.

\section{LESSON 3 AQUATIC ECOSYSTEMS}

\section{LAKES, SPRINGS \& RIVERS}

The abundant lakes, springs and rivers of Florida are an attraction for millions people every year. These systems provide arteries for transportation, irrigation for our lawns and, at times, dumping grounds for our waste. In this lesson you can research aquatic ecosystems that exist in your area. Topics on water quality as well as biodiversity are explored to better understand the interconnections within these habitats.

Activity 1 - Map Search . . . . . . . . . . . . . . . . . . . . . . . . 110 Defining and locating aquatic ecosystems will help participants become familiar with resources in their area.

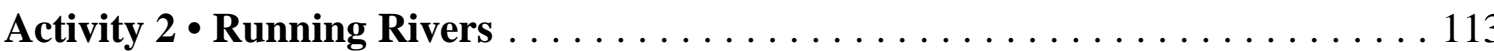

Through hands on experiments, participants will learn to measure velocity and volume related to stream flow.

Activity 3 - Stream Bank Boxes . . . . . . . . . . . . . . . . . . . 120

By creating a model, participants will discover why stream banks and pond edges are an important part of an aquatic ecosystem.

Activity $4 \cdot$ Healthy Water $=$ Healthy Ecosystems

Learn how to perform water quality tests for a pond, lake, or river and use those results to evaluate the health of the ecosystem.

Activity 5 • How Many Bugs Do You Have? . . . . . . . . . . . . . . . . . . . . . 127 Identify the different types of invertebrate organisms present in aquatic ecosystems.

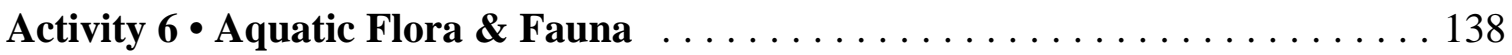

Using this crossword puzzle, participants will use clues to identify common and endangered plants and animals found in aquatic ecosystems.

\section{LESSON 4 COASTAL ECOSYSTEMS}

BEACH, ESTUARY, MARSH AND SWAMP . . . . . . . 143 
Lesson 4 is where freshwater meets saltwater, land meets ocean and people meet beach. With over $80 \%$ of this state's population living in coastal counties, the pressures of development and use are tremendous on a relatively limited amount of coastal space. An understanding of the functions and food chains in these coastal areas is presented. These concepts will help inform people and improve their awareness of the fragile nature of these critical coastal areas.

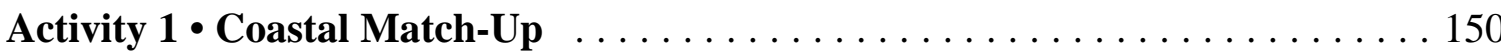

Discover Florida's diverse coastal ecosystems in addition to learning about coastal plants.

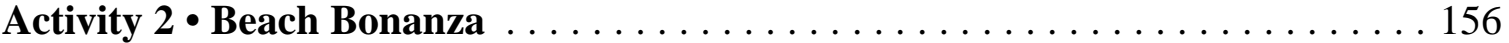

What else is a beach for besides sunbathing and fun in the ocean?

Activity 3 - Create an Estuary . . . . . . . . . . . . . . . . . . . 161

Understanding the functions of an estuary and identify animals that depend on them.

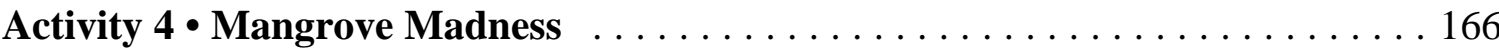

Why are mangroves important to humans and animals?

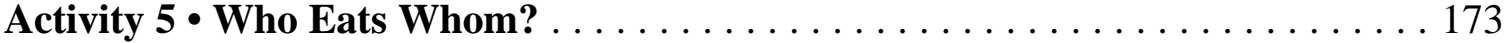

A fun activity to help participants learn about food chains.

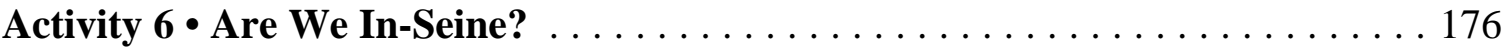

A field trip activity to provide youth the opportunity to collect and identify samples

from a local ecosystem.

LESSON 5 CORAL REEF \& OPEN OCEAN . . . . . . . . . . . . . . . . 179

Florida has the distinction of having the only barrier reef in North America. This, combined with the Gulf Stream of the Atlantic Ocean and the productive waters of the Gulf of Mexico offers a tremendous resource for fisheries and recreational activities. Lesson 5 will explore these resources and review the concepts of sustainability related to fisheries resources. Participants will also discover the fragile nature of a coral reef and suggest ways that humans might reduce impacts to this "one of a kind" resource.

Activity 1 - Water Web . . . . . . . . . . . . . . . . . . . . 188 Participants will discover the relationships in a marine ecosystems and create a mural that depicts examples of marine food chains.

Activity 2 - Ocean Harvest

Youth will learn concepts of sustainable resources and conservation.

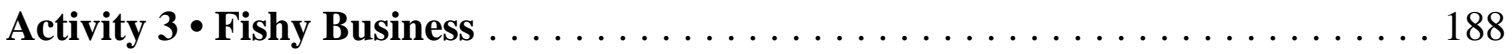

A field trip to a local fish market will help youth learn to identify fish and harvest methods.

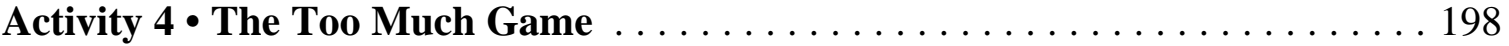

This activity will show the importance of sustaining marine resources.

Activity 5 • Where's My Home, Where's My Food? . . . . . . . . . . . . . . . . 201

Coral Reef destruction affects many animals. This activity will help youth to determine how to

protect and conserve coral reefs.

\section{STUDENT PAGES FOR DUPLICATION}

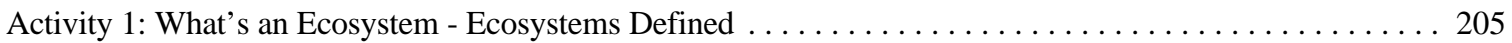

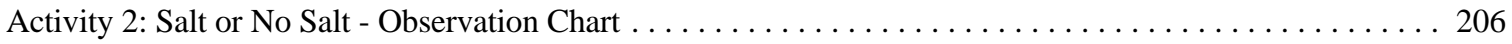

Activity 3: Water Basics - Water Cycle Pirates, Water Basics Picture Cards . . . . . . . . . . . . . . . 207-209

Activity 4: Abiotic Influences - High, Low Flags . . . . . . . . . . . . . . . . . . . . . . . 210-215

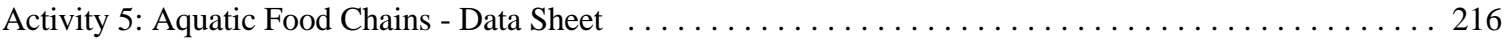


Activity 6: Food Webs: Strings Attached - Food Web Pictures . . . . . . . . . . . . . . . . . . 217-219

Activity 7: Aquatic Succession - Activity Sheet, Succession Cards . . . . . . . . . . . . . . . . . . 220-222

Activity 8: Aquatic/Marine Values - Word Search, What Are Our Values? . . . . . . . . . . . . . . . . 223-224

Lesson 2

Activity 2: Wetland Bingo - Wetland Bingo Cards . . . . . . . . . . . . . . . . . . . . . . 225-232

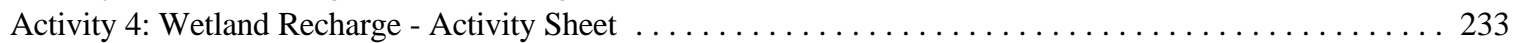

Activity 6: Wetland Types - Wetland Descriptions, Wetland Pictures . . . . . . . . . . . . . . . 234-236

Lesson 3

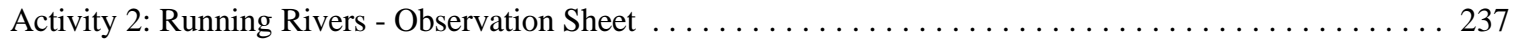

Activity 5: How Many Bugs? - Data Sheets, Pictures, Assessment Form . . . . . . . . . . . . . . . 238-243

Lesson 4

Activity 6: Aquatic Flora \& Fauna - Crossword Puzzle . . . . . . . . . . . . . . . . . . . . . . . 244

Activity 1: Coastal Match-Up - Definitions and Pictures . . . . . . . . . . . . . . . . . . . 245-247

Activity 3: Create and Estuary - Activity Pages . . . . . . . . . . . . . . . . . . . . . . . . . . 248-249

Activity 4: Mangrove Madness - Activity Pages . . . . . . . . . . . . . . . . . . . . . . . . . . . 250-251

Lesson 5

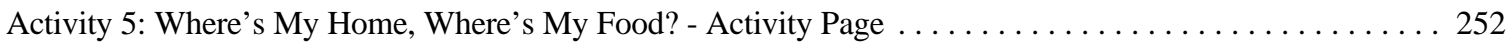

